\title{
Percepção de agricultores familiares sobre os impactos socioambientais causados pelo Porto do Açu em São João da Barra-RJ
}

\author{
Perception of family farmers on the socio-environmental impacts caused by Açu \\ Port in São João da Barra-RJ
}

\author{
José Luiz Pontes da Silva Júnior ${ }^{1}$ iD \\ Marcos Antonio Pedlowski ${ }^{2}$ iD
}

\begin{abstract}
Palavras-chave:
Agricultura familiar

Aspectos socioambientais

Impactos portuários

Conflitos costeiros

Resumo

A partir de 2007, um dos maiores empreendimentos portuários do estado do Rio de Janeiro, o Porto do Açu, foi implantado no 50 Distrito do município de São João da Barra. Para a construção de suas megaestruturas, extensas áreas de restinga foram suprimidas e um amplo processo de desapropriação de terras pertencentes a agricultores familiares foi conduzido pelo governo fluminense. O objetivo deste trabalho é verificar a percepção dos agricultores familiares que habitam o entorno do território para entender suas interrelações com o meio ambiente onde o Porto do Açu foi instalado, antes e após a chegada deste empreendimento. A partir de uma amostra aleatória de agricultores, a coleta de dados foi realizada com um questionário semiestruturado que foi construído para identificar as interferências positivas e negativas do Porto do Açu no 50 Distrito e nos sistemas agrícolas familiares que existiam em seu interior. Duas localidades foram escolhidas para a composição da amostra: Água Preta e Mato Escuro. A aplicação dos questionários ocorreu entre Maio e Agosto de 2019 com um total de 105 agricultores (65 em Água Preta e 40 em Mato Escuro). Os resultados mostraram que os agricultores consideram que o Porto do Açu interferiu diretamente na sua sustentabilidade social, econômica e ambiental. Os principais impactos ambientais e econômicos elencados pelos agricultores foram: a salinização das águas utilizadas para irrigação de suas plantações e o processo de desapropriação de suas terras. Os resultados obtidos mostram que, além de afetar a dinâmica dos ecossistemas costeiros são-joanenses, dentre eles, restinga e lagoas, o modelo de desenvolvimento econômico adotado pelo Porto do Açu alterou a qualidade de vida destes agricultores e interferiu nas suas áreas agrícolas, afetando diretamente a sua reprodução social.
\end{abstract}

\section{Keywords:}

Family Farming

Socioenvironmental Aspects

Port Impacts

Coastal Conflicts

\begin{abstract}
Ground was first broken in 2007 for the Açu Port, one of the largest port projects in the state of Rio de Janeiro, in the Fifth District of São João da Barra. Construction of its megastructures involved the clearing of extensive areas of restinga and the execution of a broad process of family-owned farmland expropriation by the Rio de Janeiro government. The objective of this study is to evaluate local family farmers' perceptions of change as a means to understand their interrelationship with the environment before and after the installation of the Açu Port. Data was collected using a semi-structured questionnaire that was designed to identify the positive and negative interventions related to the Açu Port in the Fifth District and local family farming systems. Two locations were selected for the sampling: Água Preta and Mato Escuro. Questionnaires were applied between May and August 2019 and a total of 105 farmers (65 in Água Preta and 40 in Mato Escuro) were enrolled in the study. The results show that local farmers believed the installation of the Açu Port directly interfered in their social, economic and environmental well-being. The main environmental and economic impacts listed by the farmers were: salinization of water used for irrigation of their plantations and the process of expropriation of their lands. The results obtained demonstrate that in addition to affecting the dynamics of São João da Barra coastal ecosystems, including the restinga and lagoons, the economic development model adopted by the Açu Port has affected the quality of life of these farmers, interfered with their agricultural areas and directly affected their social reproduction.
\end{abstract}




\section{INTRODUÇÃO}

O modelo de desenvolvimento econômico adotado no Brasil desde o período Colonial resultou na consolidação de uma estrutura de propriedade da terra que se caracteriza por ser excludente e concentradora. $\mathrm{Na}$ década de 1990, a agricultura familiar ganhou visibilidade política e social no processo de desenvolvimento rural do país, uma vez que era um importante fornecedor interno de alimentos, resultando na criação e implantação de políticas públicas anteriormente dedicadas às médias e às grandes propriedades (LIMA; SILVA; IWATA, 2019).

O conceito da agricultura familiar vem sendo debatido e construído nas últimas décadas por diversos setores, como instituições públicas, meio acadêmico e movimentos sociais. Entretanto, especificamente em relação ao Brasil, devido a complexa heterogeneidade regional do país e a diversidade social (e.g. de etnias e comunidades rurais) e econômica (e.g. condições produtivas e formas de trabalho agrícola e não-agrícola) dos agricultores brasileiros ainda há divergências quanto a definição unânime, precisa e operacional deste conceito (SPANEVELLO, 2008).

Segundo Tedesco (2001), apesar da literatura sobre a agricultura familiar caracterizá-la a partir de alguns pressupostos comuns (e.g. família como proprietária e produtora), é preciso considerar a ausência de linearidade entre a população de agricultores. Lamarche (1993) ressalta que a diversidade cultural, social e econômica entre os agricultores familiares é a característica central dos seus estabelecimentos familiares. Para Abramovay (1998), a agricultura familiar não pode ser tomada como um bloco compacto e homogêneo, uma vez que possui diferenciações internas e com demandas distintas quanto às políticas públicas, investimentos e financiamentos. Ele considera três atributos na definição de agricultura familiar: gestão, propriedade e trabalho familiar. Já para Lamarche (1993), a agricultura familiar é caracterizada pela pequena propriedade onde é realizada uma atividade rural por trabalhadores que apresentam relações de parentesco, residem nestas unidades produtivas e transmitem seus conhecimentos, tradições e habilidades para as próximas gerações, possibilitando assim a preservação e melhoria de várias práticas e tecnologias importantes na sustentabilidade agrícola, conservação dos recursos naturais, gerando ainda empregos, rendas e diversificação de economias locais com a produção, comercialização e consumo dos seus produtos agrícolas.

No Brasil, a agricultura familiar está dentre os segmentos produtivos que impulsionam o Produto Interno Bruto - PIB e o Valor Bruto da Produção Agropecuária - VBP. A agricultura familiar brasileira é a $8^{a}$ maior produtora de alimentos do mundo, com um faturamento anual de US $\$ 55,2$ bilhões, o que corresponde economicamente a $10 \%$ do PIB e a $38 \%$ do VBP, conforme divulgado pelo Ministério da Agricultura, Pecuária e Abastecimento - MAPA (2018). Aproximadamente 90\% dos municípios brasileiros com até $20 \mathrm{mil}$ habitantes tem a agricultura familiar como sua base econômica, e $40 \%$ da população economicamente ativa e $70 \%$ dos brasileiros ocupados no campo obtêm sua renda deste segmento, sendo que $84 \%$ dos estabelecimentos rurais pertencem a agricultores familiares, alcançando 5 milhões de famílias e 14 milhões de trabalhadores (IBGE, 2017).

Entretanto, apesar destes números expressivos, a maioria dos agricultores familiares brasileiros se encontra em situação de extrema pobreza, principalmente na região Nordeste, onde $72 \%$ dos produtores não geram lucro suficiente em seus estabelecimentos rurais familiares, o que ameaça sua sustentabilidade (DELGADO; BERGAMASCO, 2017). Segundo Plein (2011), os agricultores familiares brasileiros vivem sob os impactos econômicos e socioambientais resultantes das relações sociais e da apropriação privada dos recursos naturais. Para Brumer e Santos (2006), estes impactos atingem principalmente grupos sociais marginalizados e destituídos de poder e capital econômicos, resultando em conflitos locais e uma aguda assimetria de poderes entre os diversos atores sociais, uma vez que existe uma disputa complexa, desigual e antagônica pelo controle, acesso e uso de um determinado território, onde o ator social dominado apresenta estratégias de resistência para impedir, por exemplo, um deslocamento compulsório após a instalação de um projeto neoextrativista, tais como hidrelétricas, minerodutos e portos.

Diversos estudos têm abordado direta ou indiretamente as transformações ocorridas no município de São João da Barra em função da implantação e do início da operação do Porto do Açu, desde o seu processo de licenciamento ambiental (LATINI, 2016; PEDLOWSKI, 2017) até aos conflitos e impactos socioambientais e econômicos que este megaempreendimento 
portuário gerou (PIRES, 2009; ALVARENGA, 2013; DITTY e REZENDE, 2014; BURLA et al., 2015). Porém, ainda não foram realizadas pesquisas que verifiquem se os benefícios e expectativas propagadas pelo Porto do Açu foram de fato atingidos, bem como se esta unidade portuária está cumprindo suas contrapartidas socioambientais, especialmente aquelas destinadas aos agricultores familiares do $5 \underline{0}$ Distrito que vivem e trabalham dentro das áreas de influência direta (onde aspectos socioeconômicos e ambientais são alterados por uma relação direta de causa e efeito) e indireta (onde os impactos ocorrem com menor intensidade). Esta verificação é importante para que se possa compreender a percepção deste grupo social frente aos impactos socioambientais manifestados (e os seus riscos à biodiversidade local). Tais informações podem auxiliar na tomada de decisões de gestão ambiental que garantam a integridade das comunidades humanas e biológicas locais, minimizem a interferência nas práticas agrícolas-pecuárias, e consequentemente na sua qualidade de vida e sobrevivência socioeconômica e ainda protejam efetivamente os recursos naturais são-joanenses.

Paula, Silva e Gorayeb (2014) sugerem que os estudos de percepção ambiental podem fornecer subsídios tanto para a elaboração de projetos que abranjam as necessidades das comunidades locais afetadas por empreendimentos e permitam seu engajamento quanto para a gestão e conservação de recursos ambientais das áreas impactadas. Entretanto, no Brasil ainda são escassos estudos sobre as percepções de grupos sociais atingidos pela implantação e operação de empreendimentos portuários. Portanto, a coleta de dados a partir do ponto de vista dos agricultores familiares atingidos pelo Porto do Açu e o entendimento das mudanças socioeconômicas e ecológicas na região deveriam ser prioritários, de modo a permitir que os gestores públicos e privados atuando em São João da Barra pudessem direcionar e priorizar investimentos na agricultura local e implementar uma efetiva mitigação dos ecossistemas naturais impactados negativamente pela atividade portuária.

A partir do entendimento de que não ouvir os grupos sociais que habitavam tradicionalmente o território onde o Porto do Açu foi instalado, o presente artigo tem por objetivo apresentar os resultados de um diagnósitco realizado para estabelecer a percepção dos agricultores familiares do $5 \underline{\underline{0}}$ Distrito de São João Barra quanto aos impactos trazidos pelo empreendimento sobre suas formas de produção e reprodução social, e sobre as relações construídas pela população local com os ecossistemas naturais ao longo de um processo de integração que beira dois séculos.

\section{MATERIAIS E MÉTODOS}

O município de São João da Barra está localizado na parte mais baixa da planície Goitacá a uma altitude média de seis metros acima do nível do mar. São João da Barra possui 453,39 $\mathrm{km}^{2}$ de área territorial correspondendo a $4,7 \%$ da área total da região Norte Fluminense, tendo atualmente aproximadamente 35.000 habitantes, sendo que $20 \%$ destes ocupam a área rural (IBGE, 2020). O município está dividido em seis distritos: Sede (1ำ Distrito), Atafona (2ํ), Grussaí (3ํ), Cajueiro (4으), Pipeiras (5ํ) e Barcelos (6으). O território de São João da Barra possui uma alta diversidade de ecossistemas, que incluem restinga, lagoas costeiras, manguezais e praias oceânicas, além da proximidade com o delta do Rio Paraíba do Sul, o segundo maior do Brasil (Figura 1). 
Figura 1 - Situação e localização geográfica do município de São João da Barra, das áreas de estudo, da RPPN Fazenda Caruara, dos principais ecossistemas aquáticos e do Porto do Açu.

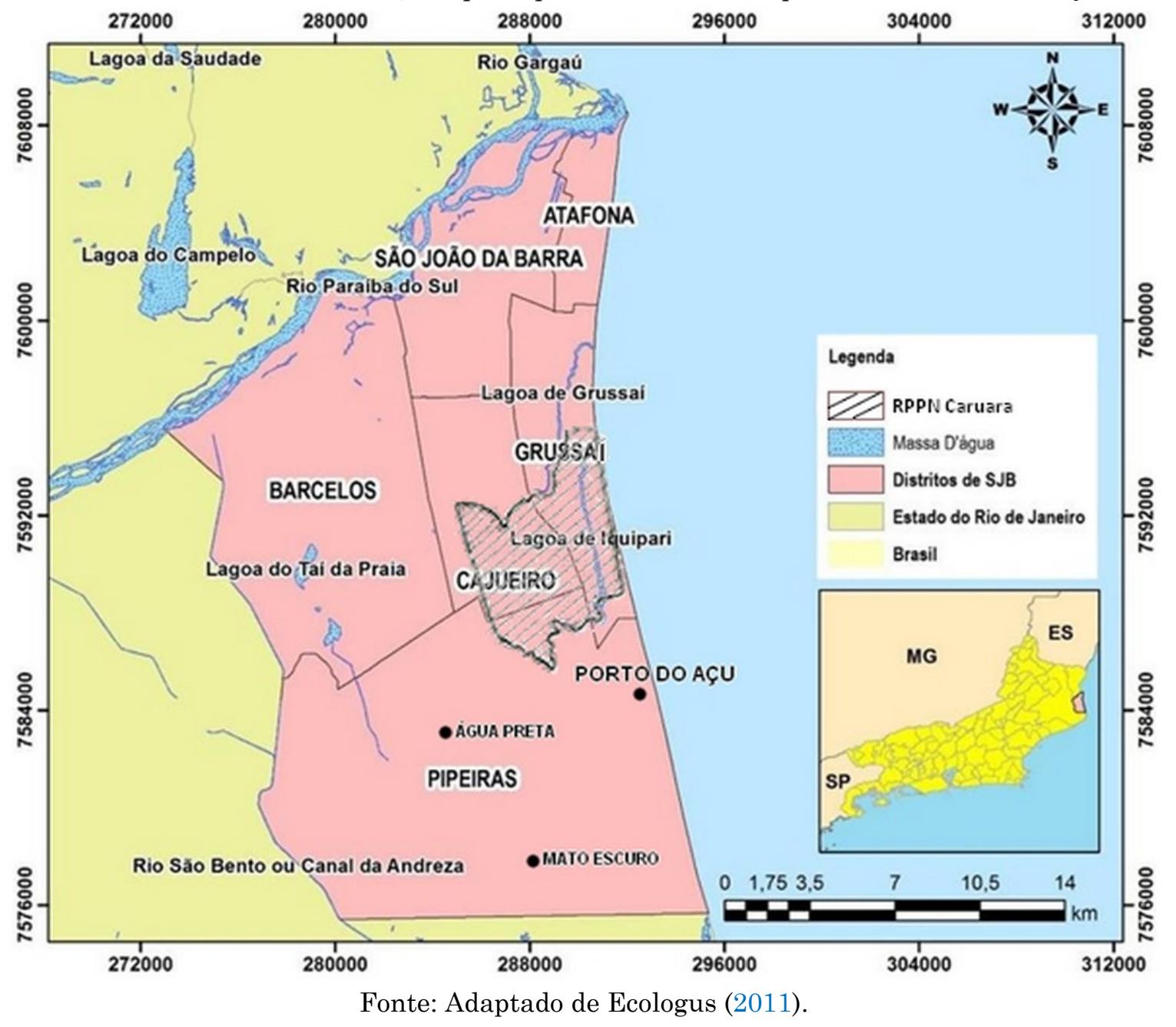

A implantação do Porto do Açu no $5^{0}$ Distrito de São João da Barra foi iniciada em 2007 e desde o seu nascedouro foi caracterizada pela ênfase em ampliar a capacidade operacional da infraestrutura nacional de transportes e de logística, sendo um dos maiores investimentos público/privado do Brasil.

Para Benevides-Guimarães, Pedlowski e Terra (2019), o Porto do Açu, assim como outros megaempreendimentos (e.g. hidrelétricos, minerários) caracterizados por uma logística complexa e de forte pegada socioambiental, foi concebido sob a égide do neodesenvolvimentismo e neoextrativismo. O primeiro termo envolve ações implantadas para viabilizar altas taxas de crescimento econômico alcançadas pelo incremento do investimento produtivo e pela viabilização das exportações de commodities. Enquanto que, o segundo conceito refere-se à adoção de uma modelo de desenvolvimento voltado na acumulação de bens extrativos (e.g. minérios, combustíveis), onde ocorre apropriação de recursos naturais através de atividades voltadas à exportação, geralmente empenhadas por enclaves coordenados por empresas nacionais e multinacionais que alcançam crescimento econômico associado aos interesses do Estado, o qual fornece apoio institucional e financeiro às organizações empresariais (MILANEZ E SANTOS, 2013). Portanto, estes dois modelos capitalistas adotados para alcançar crescimento econômico em territórios estratégicos ocasionam simultaneamente degradação socioeconômica e ecológica, externalizando seus impactos negativos às comunidades tradicionais das áreas hóspedes, como é o caso dos agricultores no $5 \underline{0}$ Distrito são-joanense.

É possível destacar como exemplo do impacto direto deste modelo adotado pelo Porto do Açu a desapropriação de terras (transferência compulsória de direitos de propriedade privada) no $5 \underline{0}$ Distrito. Este processo foi embasado pelo Decreto Estadual $n^{\circ}$ 
25.455/1999 (no qual o governo do Estado do Rio de Janeiro declarava $90 \mathrm{~km}^{2}$ como área de interesse para o desenvolvimento industrial) e executado pelo Grupo EBX e a Companhia de Desenvolvimento Industrial do Estado do Rio de Janeiro - CODIN. Esta desapropriação de terras resultou em um intenso conflito agrário, uma vez que a remoção de centenas de agricultores familiares foi marcada pela violência e uso de força policial, ilegalidade e não recebimento da devida compensação financeira por parte deste grupo social (MONIÉ, 2016).

Em sua Zona Portuária Industrial (ZPE), o Porto do Açu abriga várias empresas, com uma população estimada de 4.000 trabalhadores. Em termos de estrutura, o Porto do Açu possui dois terminais, um sistema de quebra-mares, um canal de navegação e diversos aterros hidráulicos nos quais a areia dragada para construção do canal de navegação foi depositada, inclusive nas margens da Lagoa de Iquipari (Figura 2).

Figura 2 - Instalações e construções do Porto do Açu: A (terminais TX1 e TX2), B (quebra-mar no TX2), C (empresas instaladas ao longo do canal de navegação), D (aterro hidráulico construído perto da área de restinga).
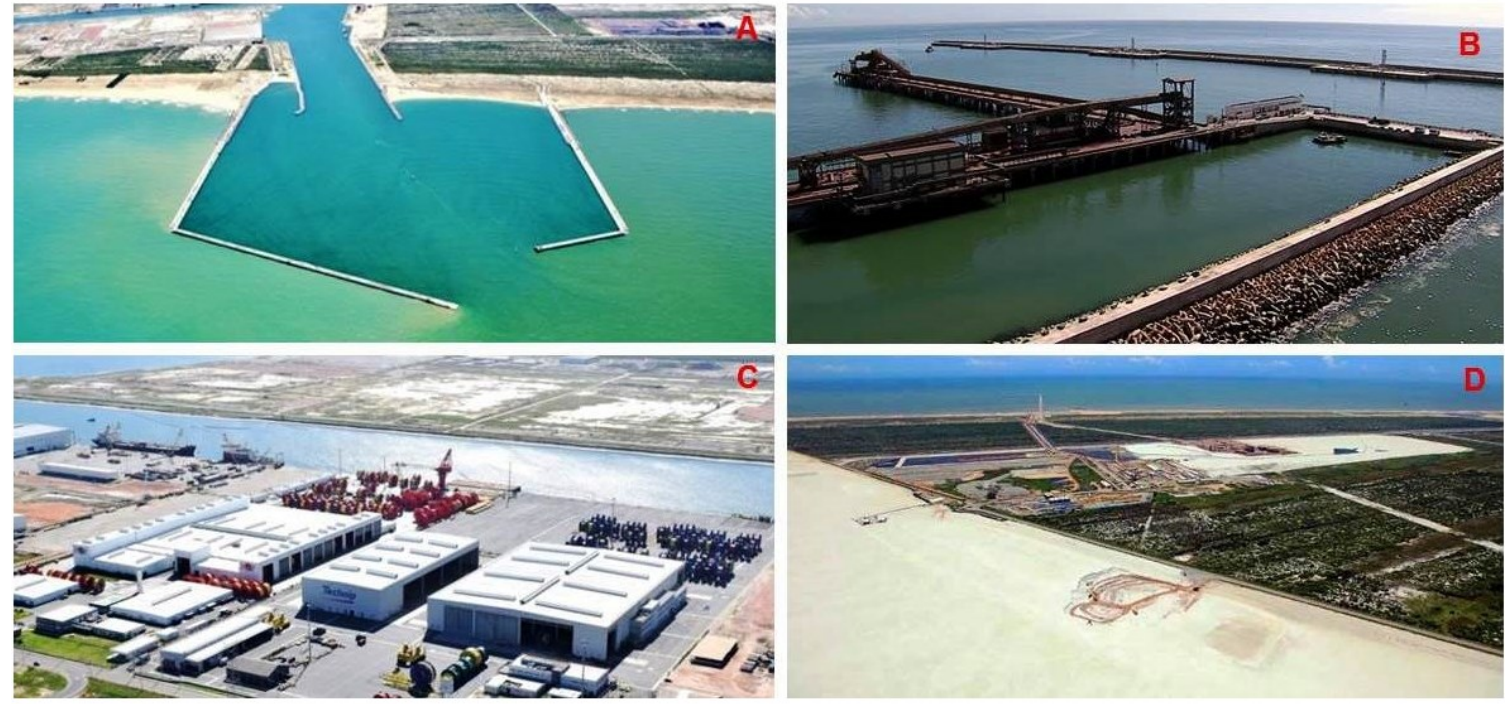

Fonte: Prefeitura Municipal de São João da Barra (2019).

O desenho experimental utilizado no presente estudo aplicou a estratégia dos "métodos mistos" que integra dados qualitativos e quantitativos para obter uma maior compreensão sobre o problema investigado (JICK, 1979). Segundo Volpato (2013), enquanto a pesquisa qualitativa possibilita uma compreensão mais aprofundada dos fenômenos sociais através da aquisição de dados via a aplicação de questionários e/ou entrevistas, a quantitativa coleta informações que podem ser quantificáveis e requerem o uso de métodos e técnicas estatísticas. Sendo estas, portanto, abordagens distintas que podem se complementar e contribuir para um melhor entendimento de um dado fenômeno.

As entrevistas realizadas com agricultores familiares foram realizadas entre os meses de maio e agosto de 2019, nas localidades de Água Preta e Mato Escuro. Um questionário padronizado contendo perguntas fechadas (na qual o entrevistado tinha que escolher entre as alternativas oferecidas) e abertas (que são aquelas que permitiram ao entrevistado responder livremente às perguntas) foi aplicado de forma sincrônica, o que garantiu que o mesmo questionário fosse aplicado a todos os participantes da amostra, permitindo a comparação das informações obtidas com os agricultores familiares com os dados disponíveis na literatura (GOLDENBERG, 1999). O processo de coleta de dados foi iniciado com o auxílio de informantes principais (primeiros agricultores desapropriados que ainda residiam no $5 \underline{0}$ Distrito), e que permitiram que o primeiro fosse identificado, para depois aplicar a técnica bola-de-neve para continuar o recrutamento dos agricultores que participaram do estudo.

Para a seleção dos agricultores que participariam da amostra foram estabelecidos três critérios: (i) ser agricultor familiar; (ii) ter a agricultura entre as principais atividades econômicas; e (iii) realizar práticas agrícolas e de pecuária no 50 Distrito. Ao início do processo de coleta de dados não foi estabelecido um 
número mínimo de agricultores a serem entrevistados. Entretanto, na medida em que as visitas foram sendo realizadas aleatoriamente nas residências e propriedades nas duas localidades, a malha amostral decaiu gradualmente, até o ponto em que não foi mais encontrado nenhum agricultor que se enquadrasse nos critérios estabelecidos e que estivesse disposto a participar da pesquisa. Entretanto, ressalta-se que, as 105 entrevistas realizadas foram consideradas como sendo suficientes para atender os objetivos da pesquisa e a análise e interpretação dos resultados, uma vez que estudos sobre a percepção e comportamento de grupos sociais consideram que amostras que contenham 30 a 60 participantes oferecem um número amostral suficiente. Pois, acima deste valor ocorreria um processo de saturação que resulta na tendência de repetição de informações coletadas que não trariam novos esclarecimentos sobre um dado fenômeno que esteja sendo estudado (BERNARD, 2000; MASON, 2010).

Todas as informações coletadas a partir da aplicação dos questionários foram organizadas em um banco de dados e separadas em categorias conforme as seções em que o instrumento foi dividido. Os dados foram processados e analisados a partir do uso de estatísticas descritivas de tendência central. As perguntas fechadas (objetivas) receberam tratamento quantitativo (análises de frequência simples), enquanto que as perguntas abertas (descritivas ou subjetivas) foram tratadas qualitativamente, após serem agrupadas em categorias de respostas. As questões que tiveram mais de uma resposta pelos entrevistados foram analisadas pela frequência relativa de ocorrência (\%) de cada um dos itens citados.

\section{RESULTADOS E DISCUSSÕES}

Um total de 105 agricultores familiares foram entrevistados, sendo que a distribuição entre as duas localidades estudadas foi de 65 de Água Preta e 40 de Mato Escuro. Nestas localidades, o gênero masculino predominou e representou $84 \%$ e $92 \%$, respectivamente. O perfil demográfico dos entrevistados foi similar nas duas áreas. Em Água Preta, 95\% dos agricultores nasceram em São João da Barra, com tempo de residência nesta localidade variando de 4 a 92 anos, sendo $77 \%$ casados, apresentando idade média de 48 anos e um baixo nível de escolaridade, já que apenas dois agricultores cursaram o ensino médio. Em relação ao tempo morando nesta localidade, $62 \%$ dos homens e $80 \%$ das mulheres residem há mais de 40 anos em Água Preta. O mesmo comportamento foi encontrado em Mato Escuro, já que todos os entrevistados eram sãojoanenses, possuindo uma idade média de 53 anos, sendo que $83 \%$ não completaram o ensino fundamental e a maioria residia na localidade há mais de 40 anos.

Este perfil demográfico é similar ao descrito em estudos realizados na mesma região (PIRES 2009, ALVARENGA, 2013, BURLA et al., 2015, PAES e ZAPPES, 2016). Segundo Oliveira et al. (2019), os agricultores familiares apresentam a desigualdade de gênero e menor nível de instrução escolar como características sociais comuns entre estes trabalhadores. De acordo com os autores, o processo de subordinação da mulher no campo e o preconceito no meio rural advindos de questões culturais de várias gerações estão diminuindo, e as mulheres estão assumindo protagonismo na agricultura familiar, não apenas como mão de obra ativa, mas também como gestoras do ambiente através de suas convicções sociais, políticas, culturais e econômicas. Para Tedesco (2001), a baixa escolaridade dificulta a organização social das populações rurais que têm na agricultura a sua principal forma de sobrevivência socioeconômica. Além disso, uma baixa escolaridade tende a interferir negativamente na capacidade de reprodução social, na auto-organização, além de diminuir o número de agricultores organizados em associações de classe e sindicatos, o que tende a diminuir a capacidade de participar do processo político. Porém, o baixo nível de escolarização dos entrevistados e a renda familiar não foram fatores que influenciaram suas percepções. E apesar da amplitude do perfil etário dentro da amostra coletada sinalizar para a presença de jovens nas atividades rurais, o baixo número de agricultores jovens atuando nas duas localidades pode indicar que o processo de sucessão geracional na agricultura familiar local não esteja ocorrendo plenamente. Spanevello (2008) aponta dois motivos principais para que isso possa ocorrer: (i) a falta de perspectiva dos filhos em seguir na ocupação agrícola-pecuária, resultando em uma migração rural crescente, e (ii) condições econômicas e sociais oferecidas pelos agricultores insuficientes para que seus filhos, majoritariamente homens, fiquem estimulados a sucedê-los.

Um dos principais impactos decorrentes da implantação do Porto do Açu sobre os 
agricultores residentes no seu entorno imediato foi a realização do processo de desapropriação de terras comandado pela CODIN. Nesse quesito, os resultados mostram que $51 \%$ dos agricultores entrevistados de Água Preta e 30\% de Mato Escuro tiveram terras desapropriadas pela CODIN. Estas desapropriações ocorreram entre 2009 a 2018 , sendo que em $45 \%$ dos casos aconteceram entre 2010 e 2011 em Água Preta, e $50 \%$ ocorreram no mesmo período em Mato Escuro. Nas duas localidades, o tamanho da área desapropriada variou entre 0,05 ha a 155 ha, tendo estas propriedades em média 11 ha.

Em Água Preta, além de um maior número de desapropriações, as propriedades desapropriadas eram maiores $(7,16 \pm 8,35 \mathrm{ha})$ do que aquelas localizadas em Mato Escuro $(5,11 \pm 5,22$ ha). Dos 45 agricultores que tiveram suas terras desapropriadas em Água Preta e Mato Escuro, nenhum foi previamente comunicado e/ou foi notificado pela CODIN que suas terras seriam objeto de desapropriação. Nas duas localidades, todos os agricultores que foram desapropriados disseram que queriam ter continuado de posse de suas terras e que não queriam vendê-las, perdê-las ou serem removidos.

Nos últimos 15 anos, São João da Barra vem passando por um forte processo de reordenamento territorial, o qual foi influenciado por interesses públicos e privados e financiado pelo capital nacional e internacional, com o objetivo manifesto de tornar o Porto do Açu o epicentro do desenvolvimento econômico regional, justificando assim as desapropriações e o processo de alteração ambiental que este megaempreendimento causou. Para Pedlowski (2017), ao contrário do discurso oficial, os controladores do Porto do Açu nunca tiveram como objetivo atender ao interesse coletivo das comunidades atingidas pelo empreendimento. Em vez disso, o que ocorreu foi um esforço explicito para excluir os habitantes tradicionais do acesso aos recursos naturais e do uso e ocupação do solo, impossibilitando assim a adoção de um modelo de desenvolvimento eficiente que permitisse uma convivência minimamente harmoniosa entre os diferentes atores presentes naquele território.

As atividades agrícola e pecuária eram a principal fonte de renda dos entrevistados antes das desapropriações, e continuam sendo atualmente. Em Água Preta e Mato Escuro, antes das desapropriações $78 \%$ e $78 \%$ dos agricultores dependiam exclusivamente do dinheiro obtido com suas plantações e produção animal para viverem, respectivamente. Por outro lado, estes valores são atualmente de $83 \%$ e $80 \%$. Antes das desapropriações a renda dos agricultores entrevistados era maior, tanto em Água Preta, onde $66 \%$ dos agricultores tinham renda mensal média de até um salário mínimo, quanto em Mato Escuro, já que 60\% dos entrevistados também afirmaram ganhar mensalmente o mesmo valor. Após as desapropriações, houve uma diminuição dos rendimentos econômicos dos entrevistados, pois $69 \%$ e $65 \%$ dos agricultores passaram a ter uma renda média de até um salário em Água Preta e Mato Escuro, respectivamente. Entranto, fica evidente que a maioria dos agricultores de Mato Escuro acreditam que o Porto do Açu trouxe mais impactos positivos (e.g. oportunidade de trabalhar no Porto e melhorar de vida, mais dinheiro para o município) do que negativos (Tabela 1). 
Tabela 1 - Opiniões dos agricultores de Água Preta e Mato Escuro quanto aos benefícios e prejuízos trazidos pelo Porto do Açu ao 50 Distrito e à agricultura familiar.

\begin{tabular}{|c|c|c|c|c|}
\hline \multicolumn{2}{|c|}{ Categoria } & Classes & Água Preta & Mato Escuro \\
\hline \multirow{12}{*}{ 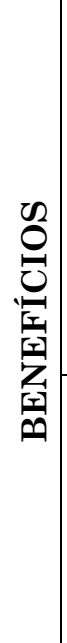 } & \multirow{7}{*}{ 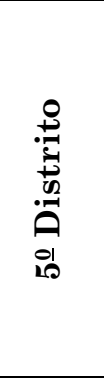 } & Mais emprego & $59 \%$ & $42 \%$ \\
\hline & & Mais urbanização & $10 \%$ & $24 \%$ \\
\hline & & Mais desenvolvimento & $14 \%$ & $12 \%$ \\
\hline & & Valorização imobiliária & $7 \%$ & $15 \%$ \\
\hline & & Maior proteção ambiental & $7 \%$ & $3 \%$ \\
\hline & & Mais escola e melhora na educação & $3 \%$ & $3 \%$ \\
\hline & & Total & $100 \%$ & $100 \%$ \\
\hline & \multirow{5}{*}{ 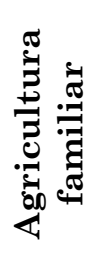 } & Mais investimento na agricultura & $33 \%$ & $20 \%$ \\
\hline & & Melhora na qualidade de vida & $33 \%$ & $20 \%$ \\
\hline & & Aumento da renda & $17 \%$ & $20 \%$ \\
\hline & & Aumento da produção agrícola & $17 \%$ & $20 \%$ \\
\hline & & Total & $100 \%$ & $100 \%$ \\
\hline \multirow{17}{*}{ 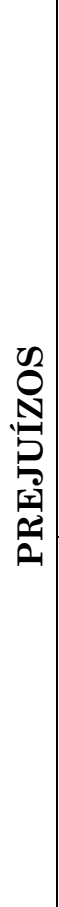 } & \multirow{10}{*}{ 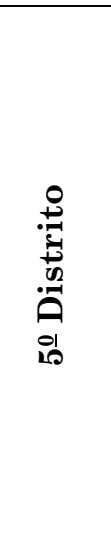 } & Desapropriação de terras & $25 \%$ & $15 \%$ \\
\hline & & Aumento da violência & $19 \%$ & $20 \%$ \\
\hline & & Piora na saúde dos moradores & $17 \%$ & $12 \%$ \\
\hline & & Falta de investimento na região & $14 \%$ & $18 \%$ \\
\hline & & Falta e perda de emprego & $10 \%$ & $10 \%$ \\
\hline & & Piora na qualidade da saúde pública & $8 \%$ & $7 \%$ \\
\hline & & Poluição do meio ambiente & $1 \%$ & $10 \%$ \\
\hline & & Dificultade de pescar em Iquipari & $4 \%$ & $6 \%$ \\
\hline & & Maior tráfego de carros e pessoas & $2 \%$ & $2 \%$ \\
\hline & & Total & $100 \%$ & $100 \%$ \\
\hline & \multirow{7}{*}{ 离 } & Redução da renda & $23 \%$ & $25 \%$ \\
\hline & & Diminuição das vendas & $16 \%$ & $19 \%$ \\
\hline & & Diminuição na colheita & $19 \%$ & $14 \%$ \\
\hline & & Piora na qualidade de vida & $19 \%$ & $14 \%$ \\
\hline & & Menos investimento na agricultura & $10 \%$ & $19 \%$ \\
\hline & & Perda de terras & $13 \%$ & $9 \%$ \\
\hline & & Total & $100 \%$ & $100 \%$ \\
\hline
\end{tabular}

Fonte: os autores (2021).

Em relação às mudanças ambientais que teriam sido causadas pela implantação do Porto do Açu, a principal foi a mudança na água, uma vez que $45 \%$ dos agricultores de Água Preta e $30 \%$ de Mato Escuro apontaram para a ocorrência de alterações de qualidade da água obtida em seus poços artesianos, principalmente em relação à cor, que ficou mais amarelada com aspecto de ferrugem, e ao cheiro e sabor, uma vez que antes era possível beber e consumir esta água (Figura 3). 
Figura 3 - Principais mudanças na água de poços artesianos dos agricultores de Água Preta e Mato Escuro após a implantação do Porto do Açu.
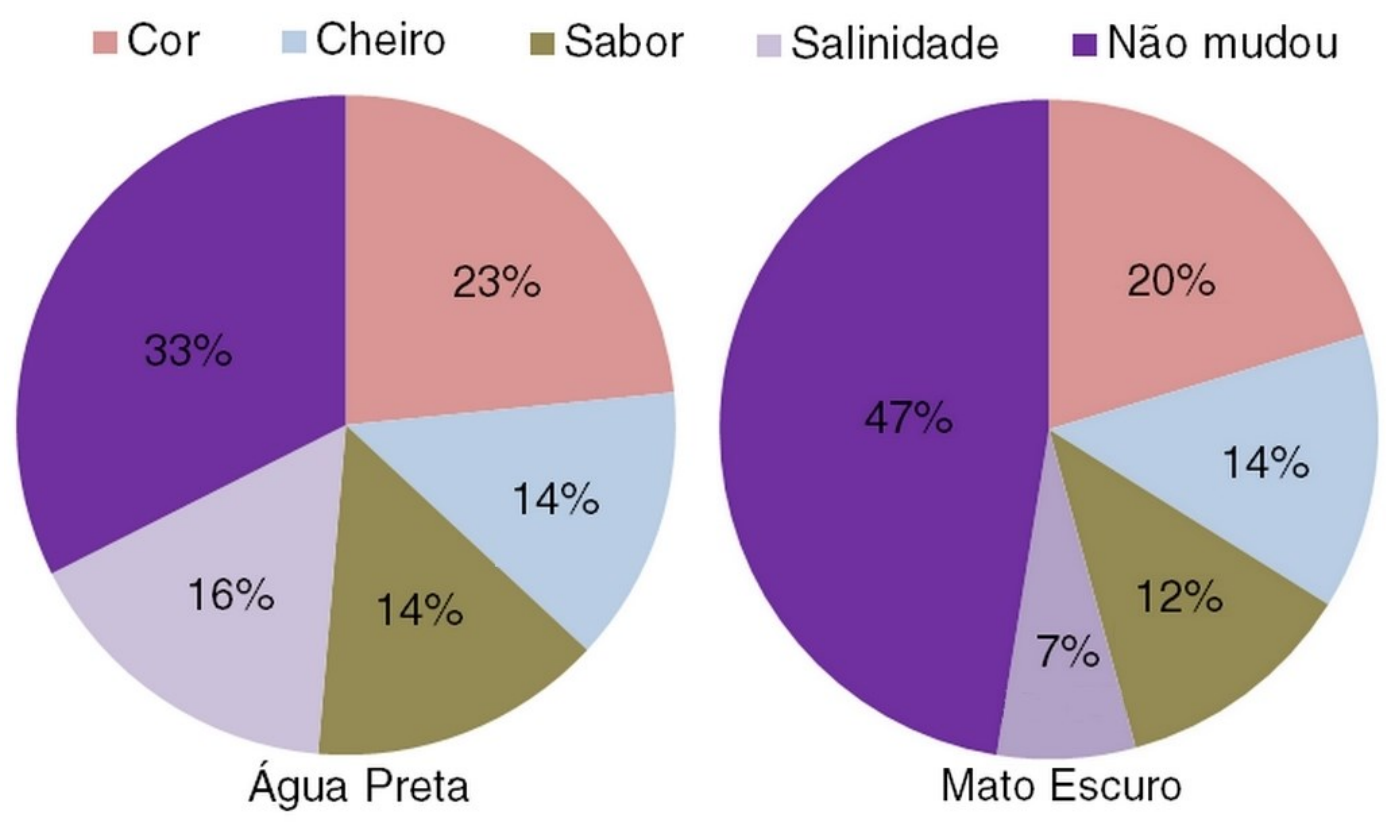

Fonte: os autores (2021).

Com a chegada do Porto do Açu, 92\% dos agricultores de Água Preta e 88\% de Mato escuro responsabilizam este empreendimento pela perda de suas terras e pelo aumento da violência. Quando questionados quanto ao futuro da agricultura familiar no $5 \underline{0}$ Distrito, para $48 \%$ dos agricultores em Água Preta e 33\% em Mato Escuro indicaram a posição de que ela se tornará inviável. Além disso, em Água Preta, $65 \%$ dos agricultores afirmaram que as mudanças negativas (e.g. perda de terras, impactos ambientais, aumento de violência) trazidas pela implantação do Porto do Açu não serão revertidas no futuro. Já em Mato Escuro, 58\% acreditam que serão revertidas.

Dos agricultores entrevistados em Água Preta e em Mato Escuro, 94\% e 93\%, respectivamente, acreditam que o Porto do Açu não trouxe melhorias à conservação ambiental. Apenas quatro agricultores de Água Preta e três de Mato Escuro notaram melhoria na conservação ambiental após a implantação do Porto do Açu, todos quanto ao reflorestamento de restinga na Reserva Particular do Patrimônio Natural - RPPN Fazenda Caruara, criada em 2012 pelo Porto do Açu (a qual possui $3.844,73$ ha e está localizada entre os limites dos $3 \underline{0}, 4^{0}$ e 50 Distritos). Em Água Preta, para $24 \%$ dos agricultores houve impactos ambientais quanto à salinização das águas dos poços artesianos e do Canal de Quitingute utilizadas para irrigação das plantações, para $19 \%$ ocorreu desmatamento de vegetação, e para $14 \%$ houve perda da fertilidade dos solos. Já em Mato Escuro, o aumento de poluição do ar pela emissão do pó de minério de ferro e a presença de animais silvestres nas suas residências foi apontado por $28 \%$ e $5 \%$ dos agricultores, respectivamente (Figura 4). Ressalta-se que, apesar da distância dos aterros, os agricultores de ambas as localidades relataram que o sal contido nas areias utilizadas para construção dos aterros é transportado pelos ventos até suas plantações, causando desde alterações morfológicas até a perda total dos plantios. 
Figura 4 - Opiniões dos agricultores sobre os impactos ambientais locais.

Salinização das águas

- Diminuiu a fertilidade do solo

- Poluição do ar por minério de ferro

- Poluição do ar pelo sal dos aterros

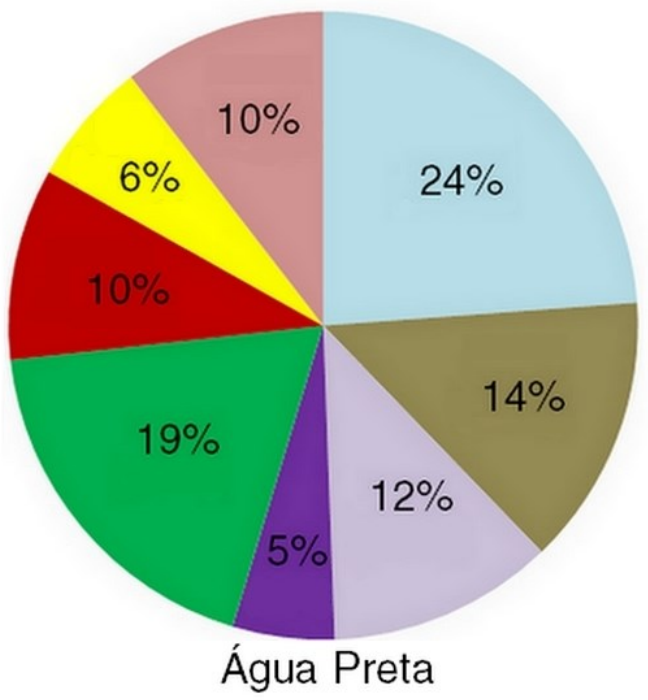

- Desmatamento de restinga

Morte de animais silvestres

Animais silvestres em casa

Morte de peixes na Lagoa de Iquipari

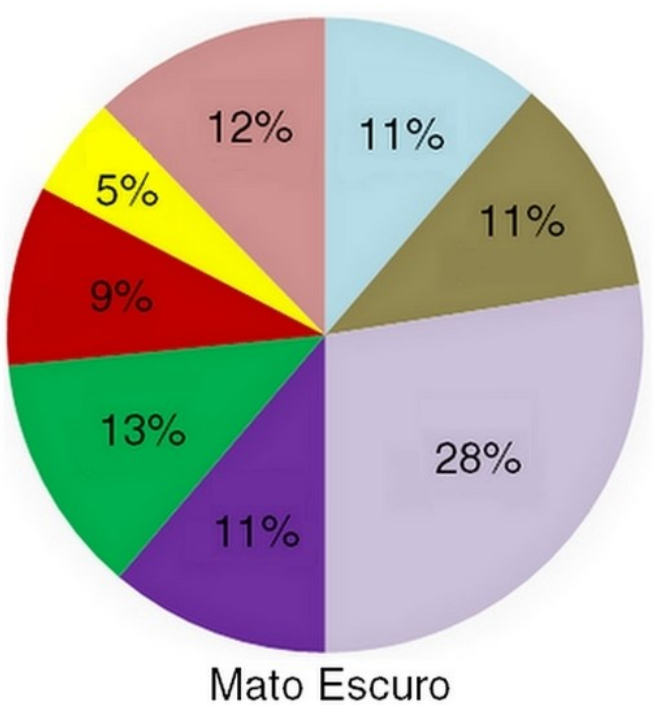

Fonte: os autores (2021).

Assim como vários outros megaempreendimentos de diferentes setores (e.g. minerário, hidrelétrico, petrolífero), os impactos negativos das megaestruturas portuárias são inerentes ao seu processo de construção e operação. Porém, estes podem ser evitados, minimizados e/ou até mesmo erradicados desde que haja: (i) comprometimento na elaboração de estudos ambientais de qualidade; (ii) busca de soluções alternativas menos impactantes mesmo que economicamente mais elevadas; (iii) atendimento à todas as condicionantes impostas pelos órgãos ambientais; (iv) transparência de informações sobre seus processos operacionais e os impactos decorrentes; (v) investimento em ações de monitoramento e projetos socioambientais efetivos; e (vi) diálogo e respeito às comunidades tradicionais das áreas de entorno que serão atingidas. Este não foi o caso do Porto do Açu e provavelmente continuará não sendo, já que não há quaisquer indícios de mudança de posicionamento de seus realizadores e financiadores nacionais e internacionais. Palma et al. (2018), também constataram esta mudança de opinião e insatisfação dos munícipes sobre o Porto do Açu quanto aos setores de meio ambiente, saúde, segurança e emprego.

\section{CONSIDERAÇÕES FINAIS}

Megaempreendimentos instalados no Brasil possuem uma narrativa similar, ao inicialmente gerar expectativas e esperança na população local (e.g. oferta de empregos, aumento de renda), para no momento posterior, ocasionar prejuízos socioeconômicos e ambientais maiores do que os benefícios propagados ao longo das suas fases de planejamento, instalação e operação. No caso do Porto do Açu este cenário é o prevalente, já que ao mesmo tempo em que abafava na mídia as repercussões negativas (e.g. desapropriações de terras dos agricultores familiares, salinização de água doce que os agricultores utilizam para a irrigação de suas plantações) tornava-se uma fonte de lucros para os setores público e privado, enquanto que sua área de entorno continua em situação vulnerável e sem perspectiva de desenvolvimento em curto e longo prazo.

Assim, não chega a ser inesperado que a percepção da maioria dos agricultores que vive nas localidades vizinhas ao Porto do Açu seja que este megaempreendimento, que acabou se tornando um enclave controlado por grandes empresas multinacionais, trouxe mais prejuízos do que benefícios tanto para o 5 $\underline{0}$ Distrito 
quanto para a agricultura familiar, principalmente relacionados à destruição do meio ambiente, à desapropriação de terras e a piora na qualidade de vida. Tal postura demonstra que os agricultores possuem uma visão ampla a cerca dos problemas socioambientais e econômicos que enfrentam desde à chegada deste megaempreendimento, e não o contrário. Importante ressaltar que, existe certa diferença de avaliação entre as duas localidades estudadas, porque em Água Preta, os agricultores possuem uma visão mais pessimista do Porto do Açu, provavelmente devido ao fato de que a maioria das desapropriações realizadas pelo governo do Rio de Janeiro estavam localizadas em sua área de influência.

A atual expansão portuária e as ações comerciais e industriais no $5 \underline{0}$ Distrito estão afetando significativamente a comunidade de agricultores familiares, tendo como principais motivos: (i) impactos socioambientais e econômicos negativos, muitos dos quais poderiam ter sido minimizados, contingenciados e até mesmo evitados; (ii) ausência de regulamentação, fiscalização e punição do poder público quanto ao processo ilegal e violento das desapropriações de terras; (iii) assimetria de poder e interesses políticos e econômicos conflitantes entre Estado, empresas privadas e população são-joanense quanto a apropriação dos recursos naturais locais e uso do território; (iv) domínio de interesses individuais em detrimento do interesse coletivo; e (v) falsa promessa de desenvolvimento econômico para a região com a chegada do Porto do Açu.

Finalmente, um aspecto de forte relevância que os resultados do presente trabalho revelam se refere ao modelo de desenvolvimento e planejamento adotado pelos controladores do Porto do Açu, na medida em que o mesmo gerou riscos e impactos que ameaçam a sustentabilidade tanto das famílias de agricultores familiares que tradicionalmente habitavam a região, quanto das áreas de alta revelância ecológica que deveriam ter sido melhor preservadas. Este resultado evidencia a existência de claro desequilíbrio no tocante às prioridades dadas ao processo de desenvolvimento econômico, as quais terminaram por impactar negativamente a população que habitava tradicionalmente o $5 \underline{0}$ Distrito, bem como a capacidade de carreamento ecológica dos ecossistemas naturais dos quais a mesma dependia para produzir e garantir sua reprodução social.

\section{REFERENCIAS}

ABRAMOVAY, R. Agricultura familiar e serviço público: novos desafios a extensão rural. Brasília. Cadernos de Ciência \& Tecnologia, v. 15, n. 1, p. 132-152, 1998. http://dx.doi.org/10.35977/01041096.cct1998.v15.8932.

ALVARENGA, F. M. Os deserdados do desenvolvimento: o caso da implantação do Complexo Portuário e Industrial do Açu e seus impactos socio-territoriais. Dissertação (Mestrado em Políticas Sociais). Universidade Estadual do Norte Fluminense Darcy Ribeiro, Campos dos Goytacazes, 120 f., 2013.

BENEVIDES-GUIMARÃES, R. M. A.; PEDLOWSKI, M. A.; TERRA, D. C. T. Dependência e expropriação estatal de terras no contexto neodesenvolvimentista/neoextrativista: implicações para a reprodução das comunidades afetadas pelo mineroduto Minas-Rio e o Complexo Portuário do Açu. Revista Desenvolvimento e Meio Ambiente, $\quad$ v. 2019. http://dx.doi.org/10.5380/dma.v51i0.60670.

BERNARD, H. R. Social Research Methods. Thousand Oaks: Sage Publications, 2000.

BRUMER, A.; SANTOS, J. V. T. Estudos agrários no Brasil: modernização, violência e lutas sociais (desenvolvimento e limites da Sociologia Rural no final do século XX). Revista Nera, v. 9, n. 9, p. 4972 , 2006.

https://doi.org/10.47946/rnera.v0i9.1432.

BURLA, R. S.; OLIVEIRA, V. P. S.; MANHÃES, C. M. C.; FRANCELINO, F. M. A.; SANTOS, J. C. O. R.; COLUCCI, M. C.; FONTES, S. C. Caracterização dos aspectos socioeconômicos e do processo produtivo agrícola dos produtores rurais da microbacia do Rio Doce, São João da Barra, RJ. VÉRTICES, v. 17, n. 1, p. 149-162, 2015. https://doi.org/10.5935/1809-2667.20150010.

DELGADO, G. C.; BERGAMASCO, S. M. P. P. (Orgs.). Agricultura familiar brasileira: desafios e perspectivas de futuro. Brasília: SEAF, 2017.

DITTY, J.M.; REZENDE, C.E. Unjust and unsustainable: A case study of the Açu port. Marine Policy, n. 45, 82-88, 2014. http://dx.doi.org/10.1016/j.marpol.2013.11.018 ECOLOGUS. Relatório de Impacto Ambiental RIMA. Infraestruturas do Distrito Industrial de São João da Barra. 124 f., 2011.

GOLDENBERG, M. A arte de pesquisar: como fazer pesquisa qualitativa em Ciências Sociais. São Paulo: Record. 107 f., 1999.

IBGE - INSTITUTO BRASILEIRO DE GEOGRAFIA E ESTATÍSTICA. Censo agropecuário. Rio de Janeiro, 2017. Disponível em: https://sidra.ibge.gov.br/pesquisa/censoagropecuario/censo-agropecuario-2017. Acesso em: 01 ago. 2020.

IBGE - INSTITUTO BRASILEIRO DE GEOGRAFIA E ESTATÍSTICA. Disponível em: https://www.ibge.gov.br/apps/populacao/projecao/in dex.html. Acesso em: 01 ago. 2020. 
JICK, T. D. Mixing qualitative and quantitative methods: triangulation in action. Administrative Science Quarterly, v. 24, n. 4, p. 602-611, 1979. https://doi.org/10.2307/2392366

LAMARCHE, H. A agricultura familiar: comparação internacional. Campinas: Ed. da UNICAMP, 1993, p. 13-3, v. 1: Uma realidade multiforme.

LATINI, J. R. A Avaliação de Impacto Ambiental (AIA) enquanto instrumento participativo e preventivo no contexto do neodesenvolvimentismo: o caso do Complexo Logístico Industrial do Porto do Açu (CIPLA). Dissertação (Mestrado em Ecologia e Recursos Naturais). Universidade Estadual do Norte Fluminense Darcy Ribeiro, Campos dos Goytacazes, 160 f., 2016.

LIMA, A. F.; SILVA, E. G. A.; IWATA, B. F. Agriculturas e agricultura familiar no Brasil: uma revisão de literatura. Retratos De Assentamentos, v. $22, \quad$ n. $1, \quad$ p. $50-68,2019$ https://doi.org/10.25059/2527-

2594/retratosdeassentamentos/2019.v22i1.332.

MINISTÉRIO DA AGRICULTURA, PECUÁRIA E ABASTECIMENTO. MAPA. Agricultura familiar. Disponível em: https://www.gov.br/agricultura/ptbr/assuntos/agricultura-familiar/agricultura-

familiar-1. Acesso em: 29 nov. 2019.

MASON, M. Sample size and Saturation in $\mathrm{PhD}$ studies using qualitative interviews. Forum: Qualitative Social Research - Sozialforschung, v. 11, n. 3, 2010. https://doi.org/10.17169/fqs11.3.1428

MILANEZ, B.; SANTOS, R. Neodesenvolvimentismo e neoextrativismo: duas faces da mesma moeda? Encontro Anual da ANPOCS, 37, p. 1-30, 2013.

MONIÉ, F. Análise geopolítica dos conflitos territoriais na área de influência do Complexo Portuário e Industrial do Açu - São João da Barra, RJ. Cadernos do Desenvolvimento Fluminense, n. 9, Rio de Janeiro, pp. 69-83, 2016. https://doi.org/10.12957/cdf.2015.28865

OLIVEIRA, M. R.; VILACA, A.; CORREIO, L. M. M. Agricultura Familiar: Reflexões Sobre Gênero. Revista de Administração de Roraima - UFRR, v. 9, n. $1, \quad$ p. $\quad 52-76, \quad 2019$ http://dx.doi.org/10.18227/2237-8057rarr.v9i1.5321

PAES, R. S.; ZAPPES, C. A. Agricultura familiar no Norte do Estado do Rio de Janeiro: identificação de manejo tradicional. Sociedade \& Natureza, v. 28, n. 3, p. 385-395, 2016. https://doi.org/10.1590/1982451320160305

PALMA, L. E. R. C. M.; SHIMOYA, A.; SHIMODA, E.; SILVA, F. F.; CASTELANO, K. L. Percepção da população de São João da Barra quanto à instalação do Complexo Portuário do Açu: comparação entre os períodos pré (2012) e pós (2015) operacionais. InterSciencePlaceInternational Scientific Journal, v. 13, n. 1, p. 145170, 2018. http://dx.doi.org/10.6020/16799844/v13n1a7

PAULA, E. M. S. D.; SILVA, E. V.; GORAYEB, A. Percepção ambiental e dinâmica geoecológica: premissas para o planejamento e gestão ambiental. Sociedade \& Natureza, v. 26, n. 3, p. 511-518, 2014. http://dx.doi.org/10.1590/1982-451320140309

PEDLOWSKI, M. A. O Completo industrialPortuário do Açu: modelo de projeto Neodesenvolvimentista ou caso aplicado de acumulação por espoliação? Boletim Petróleo, Royalties e Região, v. 15, n. 55, p. 5-10, 2017.

PIRES, B. O. Transformação Produtiva de espaços rurais e seus impactos sobre as populações locais: uma análise da construção do Complexo Portuário e Industrial do Açu no município de São João da Barra, RJ. Dissertação (Mestrado em Políticas Sociais). Universidade Estadual do Norte Fluminense Darcy Ribeiro, Campos dos Goytacazes, 111 f., 2009.

PLEIN, C.; FILIPPI, E. E. Capitalismo, agricultura familiar e mercados. Revista Desenvolvimento Regional, v. 16, n. 3, p. 98-121, 2011. http://dx.doi.org/10.17058/redes.v16i3.1545

PREFEITURA MUNICIPAL DE SÃO JOÃO DA BARRA. Disponível em: www.sjb.rj.gov.br. Acesso em: 29 nov. 2019.

SPANEVELLO, R. M. A dinâmica sucessória na agricultura familiar. Tese (Doutorado em Desenvolvimento Rural). Universidade Federal do Rio Grande do Sul, 236 f., 2008.

TEDESCO, J. C Apresentação. In: TEDESCO, J. C. (Org.). Agricultura Familiar: realidades e perspectivas. $3^{a}$ ed. Passo Fundo: Editora da UPF, p. 11-17, 2001.

VOLPATO, G. L. Ciência: da filosofia à publicação. São Paulo: Cultura Acadêmica, 6ª ed. 377f., 2013.

\section{CONTRIBUIÇÃO DOS AUTORES}

José Luiz Pontes da Silva Júnior concebeu o estudo, coletou, analisou os dados e redigiu o texto. Marcos Antonio Pedlowski analisou os dados e redigiu o texto. 